\section{Cureus}

Received 03/13/2019

Review began 03/16/2019

Review ended 04/19/2019

Published 04/23/2019

\section{(c) Copyright 2019}

Sanchez-Nadales et al. This is an open access article distributed under the terms of the Creative Commons Attribution License CC-BY 3.0., which permits unrestricted use, distribution, and reproduction in any medium, provided the original author and source are credited.

\title{
Disopyramide for Hypertrophic Cardiomyopathy
}

\author{
Alejandro Sanchez-Nadales ${ }^{1}$, Andrea Anampa-Guzmán ${ }^{2}$, Amir Khan ${ }^{1}$ \\ 1. Internal Medicine, Advocate Illinois Masonic Medical Center, Chicago, USA 2. Internal Medicine, \\ Universidad Nacional Mayor De San Marcos, Lima, PER
}

Corresponding author: Andrea Anampa-Guzmán, andreaangu11@hotmail.com

\section{Abstract}

Hypertrophic cardiomyopathy (HCM) is a cardiac disease characterized by hypertrophy of a nondilated left ventricle without any other cardiac or systemic disease that could account for observed hypertrophy. We present a female patient with the diagnosis of obstructive HCM, which is rare because sudden death is frequently the first clinical presentation. Her symptoms were resistant to medical treatment and the patient did not want invasive procedures. Disopyramide was added, and it improved her symptoms. Disopyramide is a safe and effective medication that reduces symptoms and delays the need for invasive therapy. Disopyramide was added to the treatment of the patient and it improved her symptoms.

Categories: Cardiac/Thoracic/Vascular Surgery, Cardiology, Internal Medicine Keywords: myosin, cardiomyopathy, hypertrophic

\section{Introduction}

Hypertrophic cardiomyopathy (HCM) is a cardiac disease characterized by hypertrophy of a nondilated left ventricle without any other cardiac or systemic disease that could account for observed hypertrophy [1]. HCM is caused by genetic mutations in both the thick and thin contractile myofilament proteins of the cardiac sarcomere. There are currently eight myofilament-encoding genes that are recognized as hypertrophic cardiomyopathy-associated susceptibility genes: cardiac myosin binding protein C (MYBPC3), beta-myosin heavy chain (MYH7), myosin essential light chain (MYL2), myosin regulatory light chain (MYL3), cardiac troponin T (TNNT2), cardiac troponin I (TNNI3), alpha-tropomyosin (TPM1) and cardiac alphaactin (ACTC1) [2].

HCM affects about $0.2 \%$ in the general population. The estimated annual incidence of hypertrophic cardiomyopathy is 0.47 per 100,000 children and adolescents in New England and Central Southwest regions of the United States [3]. There are two types of HCM; Obstructive HCM, characterized by the presence of left ventricular outflow tract obstruction, constitutes about $70 \%$ of cases. The remaining $30 \%$ of cases are the nonobstructive form, which lacks this characteristic. Half of the patients with the obstructive form have septal hypertrophy (obstruction at rest with $\geqslant 30 \mathrm{~mm} \mathrm{Hg}$ gradient), and the other half have a labile obstruction (obstruction with provocation and $<30 \mathrm{~mm} \mathrm{Hg}$ gradient at rest, but $\geqslant 30 \mathrm{~mm} \mathrm{Hg}$ gradient with physiologic provocation) [4].

Though patients with HCM are often asymptomatic, symptoms include chest pain associated with exertional dyspnea, palpitations due to atrial or ventricular arrhythmia, lightheadedness and syncope. This is often accompanied by a systolic murmur [4,5]. The complications of HCM are syncope, heart failure, and sudden death [1]. 


\section{Cureus}

\section{Case Presentation}

A 78-year-old Romanian female with a past medical history of obstructive HCM, moderate aortic stenosis, non-obstructive coronary artery disease, diabetes mellitus type II diet controlled and macular degeneration came to the cardiology consult. The patient has moderate to severe wall hypertrophy and significant left ventricular outflow tract (LVOT) gradient that is difficult to grade but appears greater than $50 \mathrm{~mm} \mathrm{Hg}$ (Figure 1). Systolic function is normal. She complains of occasional palpitations, cough, and dyspnea on mild activities. The patient had moderate aortic stenosis. The patient accepted medicine but declined any intervention. Edema is present in the lower extremities, and the patient claims that it has been present for over four weeks. The patient was transferred to the emergency department due to worsening shortness of breath. The patient said she cannot walk for more than half a block. The patient was on metoprolol ER $100 \mathrm{mg}$ because she could not tolerate a verapamil trial in the past. Due to this, it was decided to start disopyramide given her worsening symptoms.
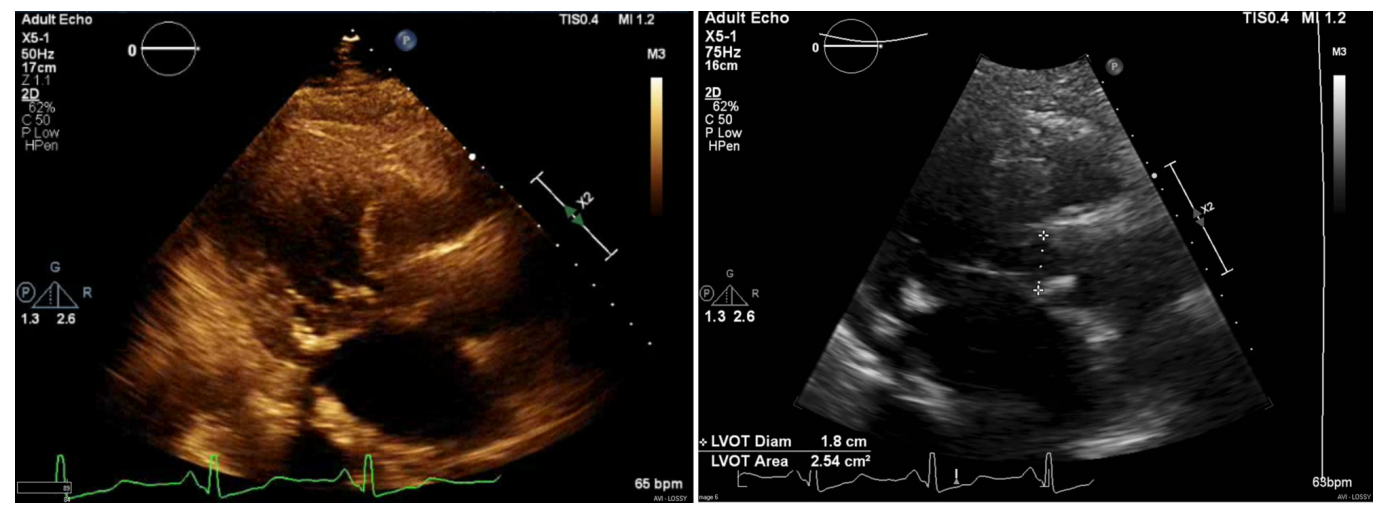

FIGURE 1: Echocardiogram images

\section{Discussion}

We presented a female patient with the diagnosis of obstructive HCM, which is rare because sudden death is frequently the first clinical presentation [4]. The initial testing in patients suspected of having HCM is a 12-lead electrocardiogram (ECG) and transthoracic echocardiography (TTE). Left ventricular hypertrophy in adults with HCM is commonly defined as a maximal left ventricular free wall thickness $\geqslant 15 \mathrm{~mm}$, with $13-14 \mathrm{~mm}$ considered borderline. Patients with HCM are advised to refrain from participating in intense competitive sports. However, they can do low intensity noncompetitive aerobic exercise as a component of a healthy lifestyle if asymptomatic [6].

Symptomatic patients are treated with beta blockers to treat angina or dyspnea in adults. Physicians should titrate this dose to achieve a resting heart rate of 60-65 beats per minute in patients who do not respond to low doses of beta blockers for angina or dyspnea. Verapamil should be used to treat angina or dyspnea in patients who do not respond to beta blockers, experience side effects, or have contraindications, and caution should be used when treating patients with high outflow gradients, heart failure, or sinus bradycardia [6]. The patient in our case did not respond to beta blockers or verapamil. Septal ablation therapies are done in patients with medication-refractory symptoms. However, our patient did not want to have procedures and was put on disopyramide. It is recommended to consider adding disopyramide to a beta blocker or verapamil therapy to treat angina or dyspnea if there is no response to these treatments alone. This should be avoided in patients with reduced systolic function [7].

Disopyramide is a class IA antiarrhythmic drug. It is a sodium channel blocker with negative 
inotropic properties that effectively reduces left ventricular outflow tract gradients in adults with HCM [8]. Patients with HCM who are persistently symptomatic despite the use of $\beta$ blockers or verapamil and have evidence of LVOT obstruction are prescribed disopyramide [7]. Disopyramide could improve LV diastolic dysfunction in patients with hypertrophic nonobstructive cardiomyopathy (HNCM) [9]. Sherrid et al. reported the long-term efficacy and safety of disopyramide in patients with obstructive HCM in a multicenter study. Two-thirds of the patients treated with disopyramide could be managed medically with amelioration of symptoms and about 50\% reduction in the subaortic gradient for over three years [10]. Disopyramide is a safe and effective medication that reduces symptoms, LVOT gradient and delays the need for invasive therapy [11]. Patients with HCM have an average life expectancy with little or no disability without need for major therapeutic interventions. Most patients with nonobstructive hypertrophic cardiomyopathy do not advance to progressive heart failure [1].

\section{Conclusions}

HCM is a disease where the myocardium has an abnormal thickening. The thickening of the heart muscle can make it difficult for the latter to pump blood. HCM is often asymptomatic. However, it can cause shortness of breath, chest pain and arrhythmias. We presented the case of a woman with symptoms resistant to medical treatment who did not want invasive procedures. Disopyramide was added, and it improved her symptoms.

\section{Additional Information}

\section{Disclosures}

Human subjects: Consent was obtained by all participants in this study. Conflicts of interest: In compliance with the ICMJE uniform disclosure form, all authors declare the following:

Payment/services info: All authors have declared that no financial support was received from any organization for the submitted work. Financial relationships: All authors have declared that they have no financial relationships at present or within the previous three years with any organizations that might have an interest in the submitted work. Other relationships: All authors have declared that there are no other relationships or activities that could appear to have influenced the submitted work.

\section{References}

1. Maron BJ, Maron MS: Hypertrophic cardiomyopathy. Lancet. 2013, 381:242-255. 10.1016/S0140-6736(12)60397-3

2. Burke MA, Cook SA, Seidman JG, Seidman CE: Clinical and mechanistic insights into the genetics of cardiomyopathy. J Am Coll Cardiol. 2016, 68:2871-2886. 10.1016/j.jacc.2016.08.079

3. Lipshultz SE, Sleeper LA, Towbin JA, et al.: The incidence of pediatric cardiomyopathy in two regions of the United States. N Engl J Med. 2003, 348:1647-1655. 10.1056/NEJMoa021715

4. Gersh BJ, Maron BJ, Bonow RO, et al.: 2011 ACCF/AHA guideline for the diagnosis and treatment of hypertrophic cardiomyopathy: a report of the American College of Cardiology Foundation/American Heart Association Task Force on Practice Guidelines. Circulation. 2011, 124:783-831. 10.1161/CIR.0b013e318223e2bd

5. Ge J, Goldschlager N: A patient with hypertrophic cardiomyopathy presenting in cardiac arrest. JAMA Intern Med. 2017, 177:573-574. 10.1001/jamainternmed.2016.8756

6. Authors Task Force members, Elliott PM, Anastasakis A, et al.: 2014 ESC Guidelines on diagnosis and management of hypertrophic cardiomyopathy: the Task Force for the Diagnosis and Management of Hypertrophic Cardiomyopathy of the European Society of Cardiology (ESC). Eur Heart J. 2014, 35:2733-2779. 10.1093/eurheartj/ehu284

7. Verlinden NJ, Coons JC: Disopyramide for hypertrophic cardiomyopathy: a pragmatic reappraisal of an old drug. Pharmacotherapy. 2015, 35:1164-1172. 10.1002/phar.1664

8. O’Connor MJ, Miller K, Shaddy RE, Lin KY, Hanna BD, Ravishankar C, Rossano JW: 


\section{Cureus}

Disopyramide use in infants and children with hypertrophic cardiomyopathy . Cardiol Young. 2018, 28:530-535. 10.1017/S1047951117002384

9. Hamada M, Ikeda S, Shigematsu Y: Advances in medical treatment of hypertrophic cardiomyopathy. J Cardiol. 2014, 64:1-10. 10.1016/j.jjcc.2014.02.022

10. Sherrid MV, Barac I, McKenna WJ, et al.: Multicenter study of the efficacy and safety of disopyramide in obstructive hypertrophic cardiomyopathy. J Am Coll Cardiol. 2005, 45:12511258. 10.1016/j.jacc.2005.01.012

11. Adler A, Fourey D, Weissler-Snir A, Hindieh W, Chan RH, Gollob MH, Rakowski H: Safety of outpatient initiation of disopyramide for obstructive hypertrophic cardiomyopathy patients. J Am Heart Assoc. 2017, 6:e005152. 10.1161/JAHA.116.005152 